\title{
Unusual case of contralateral Horner's syndrome following stellate-ganglion block: a case report and review of the literature
}

This article was published in the following Dove Press journal:

Local and Regional Anesthesia

9 October 2013

Number of times this article has been viewed

\author{
Hassan H Amhaz' \\ Larry Manders ${ }^{2}$ \\ Elie J Chidiac' \\ Vinay Pallekonda' \\ Shushovan Chakrabortty' \\ 'Department of Anesthesiology, \\ Detroit Medical Center, Detroit, \\ MI, USA; ${ }^{2}$ Wayne State University \\ School of Medicine, Detroit, MI, USA
}

\begin{abstract}
Stellate-ganglion block (SGB) is a commonly performed procedure for the treatment of numerous conditions, including upper-extremity complex regional pain syndromes and arterial insufficiency. The appropriate response to SGB includes ipsilateral Horner's syndrome and temperature elevation of affected extremity. Contralateral and bilateral Horner's syndrome following SGB are rarely seen, with only six prior cases reported. We describe a case of a 47-year-old female with right-hand pain secondary to Raynaud's phenomenon who underwent SGB with subsequent contralateral Horner's syndrome and review the literature of this rare phenomenon.
\end{abstract}

Keywords: complex regional pain syndrome, regional anesthesia, sympathetic ganglia

\section{Introduction}

Stellate-ganglion block (SGB) is a commonly performed procedure for the treatment of pain in upper-extremity, head, and neck complex regional pain syndromes and arterial insufficiency. The stellate ganglion is part of the sympathetic network formed by the inferior cervical and first thoracic ganglia that provides sympathetic efferents to the upper extremities, head, neck, and the heart. ${ }^{1,2}$ SGB can be performed with relative ease. However, several potentially fatal complications, including seizures and cardiac arrest, have been reported. ${ }^{3,4}$ As a result, image-guided techniques have been developed to reduce these risks. The appropriate response to SGB includes ipsilateral Horner's syndrome and temperature elevation of the affected extremity. Contralateral and bilateral Horner's syndrome following SGB are rarely seen, with only six prior cases being reported. ${ }^{5-8}$ We report a case of contralateral Horner's syndrome following SGB and review the literature of this rare phenomenon.

\section{Case report}

A 47-year-old female presented to our institution with right-hand pain secondary to Raynaud's phenomenon. Her pain persisted despite medical management. Physical examination revealed cold skin, hyperalgesia, allodynia, pink-to-purple discoloration of her right hand, and symmetric pupillary size. She was scheduled for a right-side SGB. The patient was placed in the supine position with her neck hyperextended and her jaw slightly opened. Monitored anesthesia care and intravenous sedation was initiated. The skin and subcutaneous tissue in the right paratracheal area was anesthetized using $3 \mathrm{~mL}$ lidocaine $1 \%$ at the level just above the C6 transverse process (Chassaignac's tubercle). The right carotid artery was retracted laterally using the index and middle
Correspondence: Shushovan
Chakrabortty
Detroit Medical Center, 3990 John R
Street - Room 290I, 2 Hudson,
Detroit, MI 4820I, USA
Tel+I 313966373 I
Fax+I 3139933889
Email shuchakrausa@yahoo.com submit your manuscript | www.dovepress.com

Dovepress

http://dx.doi.org// 0.2147/LRA.S49580 
finger from the nondominant hand, and was then advanced posteriorly squeezing the subcutaneous tissues towards the C6 transverse process. With the dominant hand, a syringe with a 22-gauge short-bevel needle was advanced perpendicularly down until Chassaignac's tubercle was felt at a depth of about $2 \mathrm{~cm}$. The needle was then withdrawn 1-2 mm. After confirming a negative aspiration, a total of $10 \mathrm{~mL}$ local anesthetic (lidocaine $1.5 \%$ and bupivacaine $0.5 \%$ at $1: 1$ ratio) was injected with intermittent aspiration. After the procedure, the patient experienced significant pain relief and subjective warmth in her right upper extremity, as well as ptosis, miosis, and conjunctival injection (Horner's syndrome) on the left, contralateral side. Right-extremity temperature was measured using surface-temperature monitoring, and showed an increase from $32.4^{\circ} \mathrm{C}$ to $34.7^{\circ} \mathrm{C}$. Right pupillary size was noted to be unchanged from baseline examination, and no facial flushing was noted. At the patient's 2-week follow up visit, she had continued pain relief and did not require additional pain medications.

\section{Discussion}

There have been only three cases of bilateral and three cases of contralateral Horner's syndrome previously reported in the literature. ${ }^{5-8}$ The exact mechanism for the development of this rare phenomenon following SGB is not well understood.

In the cervical region, the prevertebral fascia lies posterior to the sympathetic chain. At the transition from the chest to the neck, the fascia is pierced by the sympathetic chain around $\mathrm{C} 7$, and the fascia becomes anterior to the stellate ganglion. The vertebral artery also maintains a similar relationship with the sympathetic chain. From its anterior position in the upper chest, it enters the transverse foramen at the C6 level and becomes posterior to the sympathetic chain. Chassaignac's tubercle acts as an important landmark for anterior approach and also protects the vertebral artery from inadvertent puncture and injection (Figure 1). The local anesthetic solution injected at Chassaignac's tubercle level and anterior to the prevertebral fascia migrates from the anterior aspect of the fascia in rostral, caudal, and lateral directions. ${ }^{9}$ The injectate obeys the fascial plane and gradually passes anteriorly as it migrates caudally. A magnetic resonance imaging study during SGB also showed that local anesthetic was not delivered to the stellate ganglion but passed anteriorly to it. ${ }^{10}$ The sympathetic neural blockade by SGB takes place mostly in the upper levels of the sympathetic chain.

Medial angulation of the needle, injection behind the longus colli muscle, or a larger volume of the local anesthetic is usually blamed for local anesthetic migration to the contralateral side. ${ }^{8}$ Contralateral and bilateral Horner's syndromes are also reported with standard technique of needle placement and even with a small volume of local anesthetic, suggesting cross-variations in stellate ganglion innervation. ${ }^{5-7}$ Further explanation could be seen in patients who suffer from spinal cord lesions or dysautonomias. It is

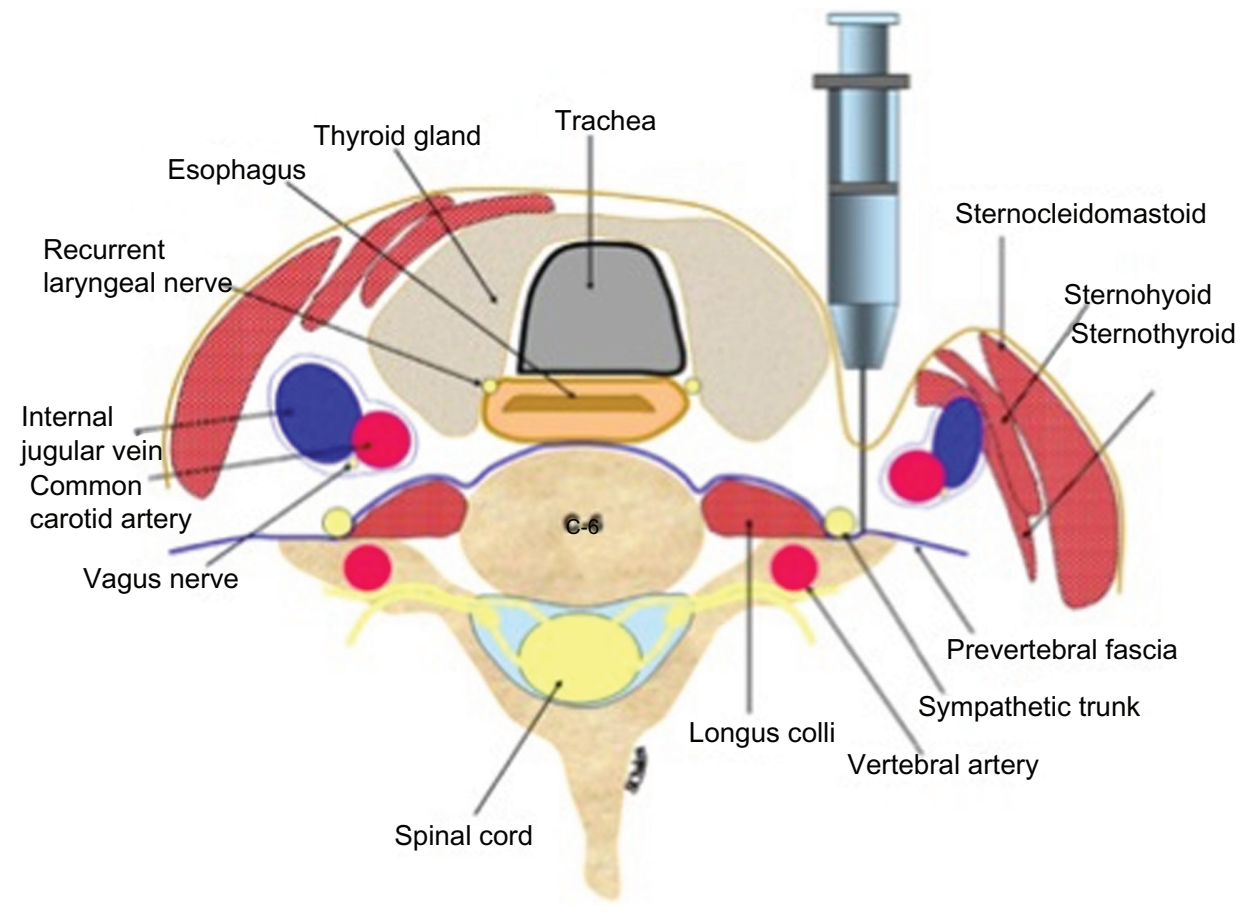

Figure I Cross-sectional anatomy at the C5-C6 level. 
believed that inhibition of the ciliospinal center of Budge results in an excitatory sympathetic response leading to ipsilateral pupillary dilation, facial hyperhidrosis, and lid lift, and therefore a paradoxical contralateral Horner's syndrome. ${ }^{11}$ Previous literature showed that increased hand warming and facial skin blood flow occurred bilaterally in about $50 \%$ of cases after unilateral SGB. ${ }^{12,13}$ These findings suggest that bilateral sympathetic blockade occurs commonly to a degree to produce these functional changes, but not enough to produce gross anatomic changes, including Horner's syndrome. In our present case, pain relief was sustained and long lasting, as evidenced by a postprocedure follow-up 2 weeks later. We initially thought that the sympathetic block on the contralateral side as evidenced by the development of Horner's syndrome would not be beneficial for her. In light of the beneficial effects, we are postulating that the sympathetic innervation of the right upper extremity was successfully blocked despite Horner's syndrome of the left side.

\section{Conclusion}

Contralateral Horner's syndrome is a rare and poorly understood phenomenon following SGB. With the adjacent neurovascular structures, uncontrolled migration of local anesthetic and frequently seen anatomic variations, increased vigilance is warranted in patients receiving SGB. When performed safely, SGB can provide patients with excellent pain relief.

\section{Disclosure}

The authors report no conflicts of interest in this work.

\section{References}

1. Wong W. Spinal nerve blocks. In: Williams AL, Murtagh FR, editors. Handbook of Diagnostic and Therapeutic Spine Procedures. St Louis (MO): Mosby; 2002:20-40.

2. Erickson SJ, Hogan QH. CT-guided injection of the stellate ganglion: description of technique and efficacy of sympathetic blockade. Radiology. 1993;188:707-709.

3. Rastogi S, Tripathi S. Cardiac arrest following stellate ganglion block performed under ultrasound guidance. Anaesthesia. 2010;65:1042.

4. Chaturvedi A, Dash H. Locked-in syndrome during stellate ganglion block. Indian J Anaesth. 2010;54:324-326.

5. Allen G, Samson B. Contralateral Horner's syndrome following stellate ganglion block. Can Anesth Soc J. 1986;3:112-113.

6. Manchikanti L. Bilateral Horner's syndrome following stellate ganglion block. Anesth Rev. 1990;17:41-43.

7. Wallace MS, Milholland AV. Contralateral spread of local anesthetics with stellate ganglion block. Reg Anesth. 1993;18:55-59.

8. Warrick JW. Stellate ganglion block in the treatment of Ménière's disease and symptomatic relief of tinnitus. Br J Anaesth. 1969;41:699-702.

9. Anaesthesia UK. Stellate ganglion block (cervicothoracic sympathetic block). 2005. Available from: http://www.frca.co.uk/article. aspx?articleid=100538. Accessed August 5, 2013.

10. Hogan QH, Erickson SJ, Haddox JD, Abram SE. The spread of solutions during stellate ganglion block. Reg Anesth. 1992;17:78-83.

11. Kawasaki A. Disorders of pupillary function, accommodation, and lacrimation. In: Miller N, Newman N, editors. Walsh and Hoyt's Clinical Neuro-ophthalmology. 6th ed. Philadelphia: Lippincott Williams \& Wilkins; 2005:754.

12. Hogan QH, Taylor ML, Goldstein M, Stevens R, Kettler R. Success rates in producing sympathetic blockade by paratracheal injection. Clin J Pain. 1994;10:139-145.

13. Kakuyama M, Toda H, Osawa M, Fukuda K. The bilateral effect of stellate ganglion block on the facial skin blood flow. Reg Anesth Pain Med. 2000;25:389-392.

\section{Publish your work in this journal}

Local and Regional Anesthesia is an international, peer-reviewed, open access journal publishing on the development, pharmacology, delivery and targeting and clinical use of local and regional anesthetics and analgesics. The journal welcomes submitted papers covering original research, basic science, clinical studies, reviews \& evaluations,

\section{Dovepress}

guidelines, expert opinion and commentary, case reports and extended reports. The manuscript management system is completely online and includes a very quick and fair peer-review system, which is all easy to use. Visit http://www.dovepress.com/testimonials.php to read real quotes from published authors. 